\title{
I SEMINÁRIO DE CONSERVAÇÃO DE IGREJAS E ARTE SACRA DE SANTA CATARINA
}

\begin{abstract}
KAREN KREMER
Fundação Catarinense de Cultura (FCC), Florianópolis, Santa Catarina, Brasil Mestre pela Universidade Federal de Santa Catarina; especialização em Conservação e Restauração de Esculturas em Madeira Dourada e Policromada pela Università Internazionale Dell'Arte (Itália); licenciatura em Educação Artística pela Universidade do Estado de Santa Catarina. Funcionária pública estadual, conservadora-restauradora no Ateliê de Conservação e Restauração de Bens Móveis e Integrados (Atecor), na Fundação Catarinense de Cultura (FCC). E-mail: karenkremer@gmail.com.
\end{abstract}

\section{LETÍCIA DA SILVA GONDIM}

Fundação Catarinense de Cultura (FCC), Florianópolis, Santa Catarina, Brasil Graduada em história pela Universidade Federal de Santa Catarina e graduanda em Museologia pela mesma universidade. Estagiária do Ateliê de Conservação e Restauração de Bens Móveis e Integrados (Atecor), na Fundação Catarinense de Cultura (FCC).

E-mail: leticiasgondim@gmail.com.

\section{MARCELINO DONIZETH DE MELO}

Fundação Catarinense de Cultura (FCC), Florianópolis, Santa Catarina, Brasil Especialista em Artes Visuais Contemporânea pela Universidade do Estado de Santa Catarina; bacharel em Artes Plásticas pela mesma universidade. Funcionário público estadual, conservador-restaurador no Ateliê de Conservação e Restauração de Bens Móveis e Integrados (Atecor), na Fundação Catarinense de Cultura (FCC).

E-mail: m.celo50@hotmail.com.

RECEBIDO

20/08/2015

APROVADO 23/11/2015

http://dx.doi.org/10.11606/issn.1980-4466.v0i20p195-206 


\section{SEMINÁRIO DE CONSERVAÇÃO DE IGREJAS E ARTE}

SACRA DE SANTA CATARINA

KAREN KREMER, LETíCIA DA SILVA GONDIM E MARCELINO DONIZETH DE MELO

\section{RESUMO}

O I Seminário de Conservação de Igrejas e Arte Sacra de Santa Catarina foi pensado de forma a valorizar os bens culturais sacros móveis, imóveis e integrados da Igreja Católica no estado. O objetivo foi chamar a atenção de párocos, padres e administradores das paróquias e igrejas quanto à importância da conservação preventiva desses bens.

PALAVRAS-CHAVE

Conservação preventiva. Arte sacra. Patrimônio cultural. 


\section{INTRODUÇÃO}

No estado de Santa Catarina existe um grande número, embora desconhecido, de bens culturais pertencentes à Igreja que podem ser considerados patrimônio por seu alto valor histórico, estético, artístico e cultural. De todos esses bens, somente 30 igrejas são tombadas e até o momento nenhum bem móvel nem integrado foi tombado pelo estado. É desconhecida a quantidade e o estado de conservação de grande parte dos bens culturais móveis presentes nos edifícios religiosos, já que a Fundação Catarinense de Cultura (FCC), através do Ateliê de Conservação e Restauração de Bens Culturais Móveis e Integrados (Atecor) ${ }^{1}$ inventariou, ${ }^{2}$ até o momento, apenas 17 igrejas tombadas. É necessário, portanto, ampliar esta ação para outras igrejas, bem como realizar o inventário dos bens integrados que ainda não foram contemplados. O inventário foi apenas um primeiro passo, pois ainda há muito a ser feito em termos de ações eficazes e efetivas para a salvaguarda desses bens.

\footnotetext{
1. O Ateliê de Conservação-Restauração de Bens Culturais Móveis (Atecor) foi criado em 1982 pelo artista plástico e especialista em conservação-restauração de bens culturais móveis, Aldo João Nunes. É um setor da Diretoria de Preservação do Patrimônio Cultural da Fundação Catarinense de Cultura (FCC) que presta assessoria às unidades museológicas da FCC e fiscaliza as intervenções em bens tombados pelo estado de Santa Catarina, além de ser um ateliê de restauração especializado em pintura de cavalete e esculturas douradas e policromadas.

2. Em 2008, o Atecor realizou o inventário de cinco igrejas da região metropolitana de Florianópolis, no ano seguinte foram inventariadas mais sete igrejas e atualmente está sendo finalizada a terceira etapa do Inventário de Bens Sacros, com mais cinco igrejas.
} 
Constata-se a crescente deterioração do patrimônio sacro e o quase nulo emprego de recursos humanos e financeiros destinados aos procedimentos de conservação. Em geral, somente se atenta à salvaguarda quando o bem já se encontra em estado avançado de degradação, necessitando de restauração, que é sempre uma ação mais radical e onerosa. A preservação do acervo depende de atitudes simples executadas por seu responsável, que deverá, antes de tudo, conhecê-lo para melhor preservá-lo. Observar, defender, respeitar e dar manutenção são princípios básicos de ação conservativa. Na maior parte das vezes, não são tomadas providências simples para sanar problemas por falta de conhecimento dos procedimentos e ações de manutenção e conservação que poderiam estancar, ou ao menos amenizar, a deterioração. Nas igrejas catarinenses, quase nunca se segue a máxima do "conservar para não restaurar".

É nesse contexto que surge o I Seminário de Conservação de Igrejas e Arte Sacra de Santa Catarina como mais um passo rumo ao objetivo de salvaguardar o valioso acervo sacro catarinense.

\section{A IGREJA E O ESTADO}

Visando criar mecanismos para a preservação dos bens sacros tombados, buscou-se estreitar a relação institucional entre o estado de Santa Catarina e a Igreja Católica. Entre a Federação e o Vaticano essa aproximação já existe, efetivada pelo Decreto n. 7.107, de 11 de fevereiro de 2010, que promulga o acordo entre o governo da República Federativa do Brasil e a Santa Sé, relativo ao Estatuto Jurídico da Igreja Católica no Brasil, firmado na Cidade do Vaticano em 13 de novembro de 2008. O Acordo consolida, em um só documento, todos os atos legais até então vigentes. É composto por 20 artigos, dentre os quais destacamos o caput do artigo $6^{\circ}$ :

As Altas Partes reconhecem que o patrimônio histórico, artístico e cultural da Igreja Católica, assim como os documentos custodiados nos seus arquivos e bibliotecas, constituem parte relevante do patrimônio cultural brasileiro e continuarão a cooperar para salvaguardar, valorizar e promover a fruição dos bens, móveis e imóveis, de propriedade da Igreja Católica ou de outras pessoas jurídicas eclesiásticas, que sejam considerados pelo Brasil como parte de seu patrimônio cultural e artístico. 
Apesar da boa relação já existente, houve uma maior aproximação entre o estado de Santa Catarina e a Igreja Católica a partir de 2014, quando se reuniram, na Mitra Metropolitana de Florianópolis, membros da Diretoria de Patrimônio Cultural da Fundação Catarinense de Cultura com o Arcebispo Dom Wilson Tadeu Jönck e membros da Comissão Arquidiocesana de Arte Sacra de Florianópolis para unir forças em prol da salvaguarda dos bens sacros no estado. Vários encontros entre as partes seguiram-se a esse, nos quais foi confirmada a necessidade de salvaguardar os bens culturais da Igreja no estado e disseminar a tradição de preservação, já que impera a falta de informação quanto à forma adequada de se preservar os bens culturais e quanto aos corretos procedimentos de manutenção dos edifícios tombados.

Como consequência dessas conversas, foi acordado que se realizassem seminários e cursos, iniciando pelo I Seminário de Conservação de Igrejas e Arte Sacra de Santa Catarina, realizado em parceria entre a FCC e a Arquidiocese de Florianópolis, com o intuito de abranger todo o estado.

\section{O SEMINÁRIO}

O I Seminário de Conservação de Igrejas e Arte Sacra de Santa Catarina foi realizado no dia 21 de outubro de 2014 pela FCC, por meio da Diretoria de Preservação do Patrimônio Cultural (DPPC) e o Atecor em parceria com a Arquidiocese de Florianópolis. O seminário foi pensado de forma a valorizar os bens culturais sacros da Igreja no estado, com o objetivo de chamar a atenção de párocos, padres e administradores das paróquias e igrejas (seu público alvo) quanto à importância da conservação preventiva desses bens, discorrendo sobre as necessárias medidas de ordem prática a serem tomadas para a correta conservação das igrejas e de seus bens culturais móveis e integrados, tais como: retábulos, pinturas murais, imagens sacras, pinturas de cavaletes, vestuários, livros, documentos etc.

O público ao qual o evento foi destinado compareceu de forma bastante satisfatória, superando todas as expectativas, tanto em número quanto na participação, tirando dúvidas e tecendo comentários.

O seminário contou com diversos palestrantes, em sua maioria membros da Igreja e funcionários públicos ligados às questões de preservação do patrimônio cultural. Buscou-se uma integração entre diversas áreas: arquitetura, conservação, restauração e história. Procurou-se, ainda, esclarecer 
quanto às ações de preservação empreendidas pelo estado de Santa Catarina no âmbito do patrimônio religioso, e informar os procedimentos a serem adotados para solicitar recursos públicos para obras de restauração em bens tombados.

Durante o seminário, buscou-se demonstrar como ações de manutenção efetuadas de forma inadequada contribuem para a deterioração do bem. É de extrema importância que os responsáveis por cuidar, guardar e preservar o patrimônio tenham consciência do valor desses bens e recebam informações quanto aos procedimentos e ações de manutenção e conservação adequadas.

A partir das palestras proferidas no seminário, foi publicado o Caderno de orientações: conservação de bens culturais sacros no estado de Santa Catarina, pela FCC Edições, que está também disponível em versão digital no site da FCC. Os interessados podem ter acesso ao conteúdo de todas as palestras e também às leis de tombamento consultando o Caderno de orientações. A seguir, encontram-se alguns pontos importantes levantados no seminário.
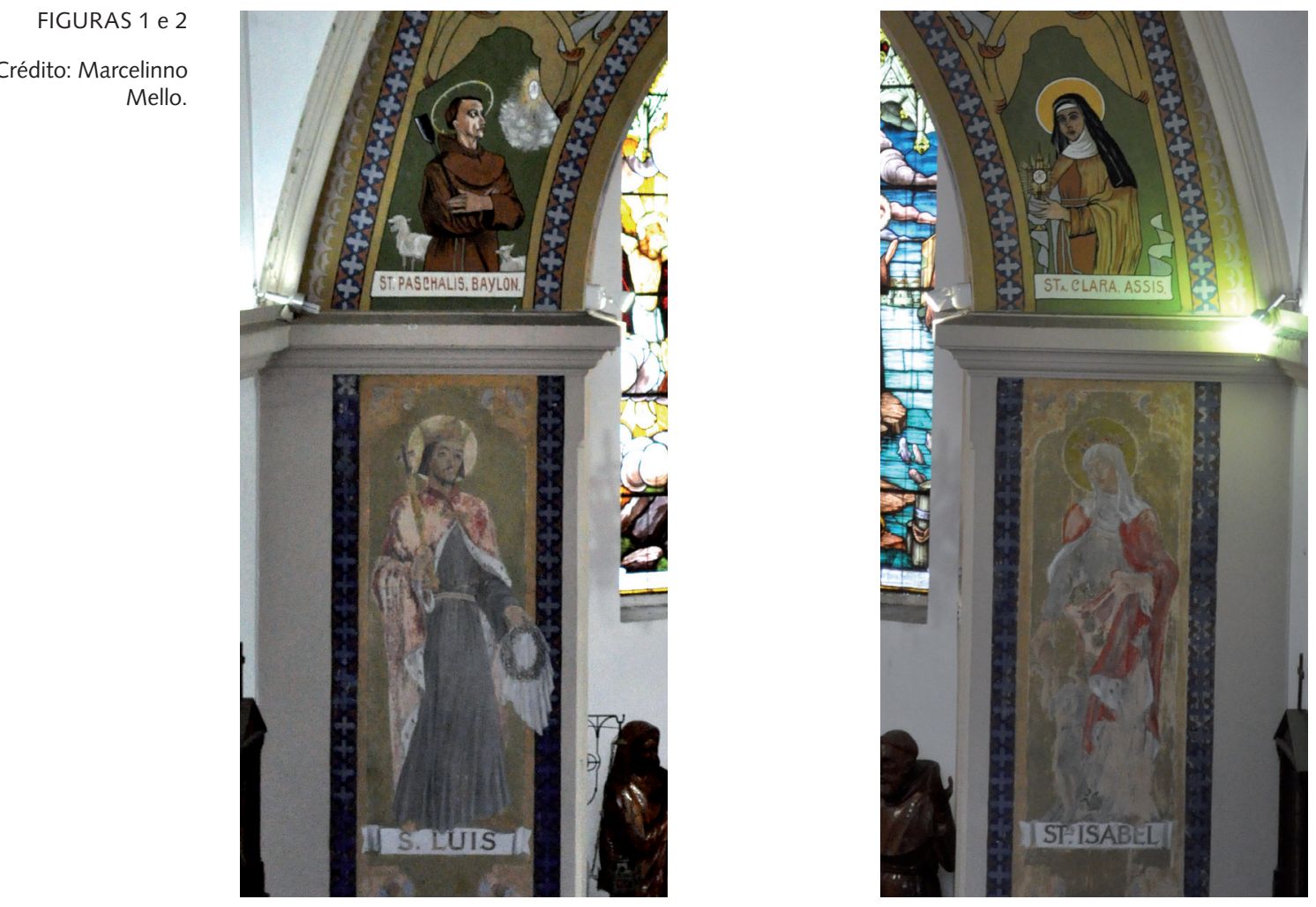
Primeiro foi dada atenção especial à limpeza do piso, do mobiliário e dos bens móveis e integrados. A limpeza faz parte da conservação, portanto quem a realiza deve ser capacitado para tal finalidade, pois uma limpeza executada erroneamente pode resultar em graves danos, como ocorreu com pintura mural (figuras o1 e 02) da Igreja São José do Patrocínio, em Lages (SC). A parte superior do arco cruzeiro, de mais difícil acesso, foi preservada, mas suas laterais foram constantemente limpas com vassouras ou escovas ao longo dos anos, danificando a camada pictórica.

Outro ponto a se destacar é a importância de uma rotina de monitoramento e controle da temperatura e umidade relativa do ar, circulação do ar, presença de infiltrações, vazamentos, goteiras e outras fontes de umidade, poluição do ar proveniente do exterior ou do interior (como a causada pela queima de velas), incidência de luz solar direta sobre os bens e presença de excremento de cupim indicando infestações.

Além disso, também é importante atentar à prevenção de riscos contra intempéries. Incêndios, enchentes, inundações e infiltrações causam muitos danos que podem ser evitados ou minimizados se as igrejas tiverem um planejamento adequado, com programas de proteção contra desastres.

Foi lembrado, ainda, que no Brasil existe o problema de roubos, furtos ${ }^{3}$ e ações de vandalismo que não poupam as igrejas. Algumas pinturas e imagens sacras têm altíssimo valor monetário no mercado negro de obras de arte e antiguidades. ${ }^{4}$ Há também o risco iminente de vandalismo e atentados às imagens sacras, promovidos por motivações religiosas. É necessário investir em segurança para minimizar esse risco aos bens sacros, buscando a melhor forma de equilíbrio entre a viabilidade de veneração da imagem pela comunidade católica e sua proteção contra roubos. É recomendada a utilização de câmeras de segurança, vigilância e alarme contra furto. Convém instalar alarmes individuais para cada imagem sacra, dando prioridade àquelas de maior valor histórico-artístico.

3. O Ministério Público de Minas Gerais (MPMG) tem um reconhecido trabalho de recuperação de obras sacras furtadas e faz campanha contra o comércio clandestino de arte sacra e incentiva que se denuncie esse tipo crime.

4. Em Santa Catarina tem-se conhecido caso da imagem de São Miguel Arcanjo, furtada em 1979. Ela foi encontrada em 2011 pela Polícia Federal em um antiquário no Rio de Janeiro, após denúncia do Iphan. 
Foi dito ainda que é fundamental a conscientização da comunidade para colaborar na manutenção e preservação das obras sacras como também de todo o complexo edificado.

A conservação de igrejas é similar a de museus em muitos aspectos, mas existem algumas especificidades, principalmente em ocasiões especiais como casamentos e procissões. Foram dados esclarecimentos sobre como agir nessas situações.

Nos casamentos e também em festas religiosas, os decoradores, muitas vezes, usam percevejos, pregos ou fitas adesivas nos bancos e nos altares, danificando a policromia e o suporte. Também usam muitas flores que podem trazer insetos para dentro da igreja e alterar a umidade relativa do ar. Os arranjos de flores deveriam ser protegidos com suporte próprio para não entrar em contato direto com a madeira e a policromia dos bens integrados e bancos, evitando a passagem de umidade para os objetos e móveis. O uso de flash para fotografias também é corriqueiro. Independentemente da ocasião, o uso de velas nas igrejas também é um problema recorrente, especialmente quando acesas próximas de bens móveis ou integrados. As velas agridem pelo calor, luz e fumaça que emitem, além da parafina que, ao derreter, escorre sobre o retábulo, às vezes atingindo também algum bem móvel. As velas também podem causar incêndios se não forem tomadas as devidas precauções.

Nas procissões, as imagens sacras sofrem com a exposição às condições climáticas externas e correm muitos riscos pelo manuseio intenso e nem sempre adequado. Recomenda-se o uso de luvas limpas para tocar na imagem. Deve-se ter muita cautela ao colocar a imagem no andor, que deve ser bastante seguro. Se necessário, podem-se fazer adaptações no andor ou confeccionar um novo, para propiciar maior segurança à imagem e evitar danos, como furos. Durante a procissão, é necessário proteger as imagens contra as intempéries, evitando que receba luz do sol diretamente ou respingos de chuva. No caso de esculturas de grande valor histórico e artístico, o ideal é que fiquem sempre protegidas, não saindo nunca em procissão, que é quando os riscos de dano são sempre potencializados. Uma opção para essas imagens seria a confecção de uma réplica que saia em procissão enquanto a imagem histórica permanece em segurança. 
FIGURAS 3 e 4

Imagem de Santo Antônio dos Anjos de Laguna. Crédito: Arquivo IPHAN.
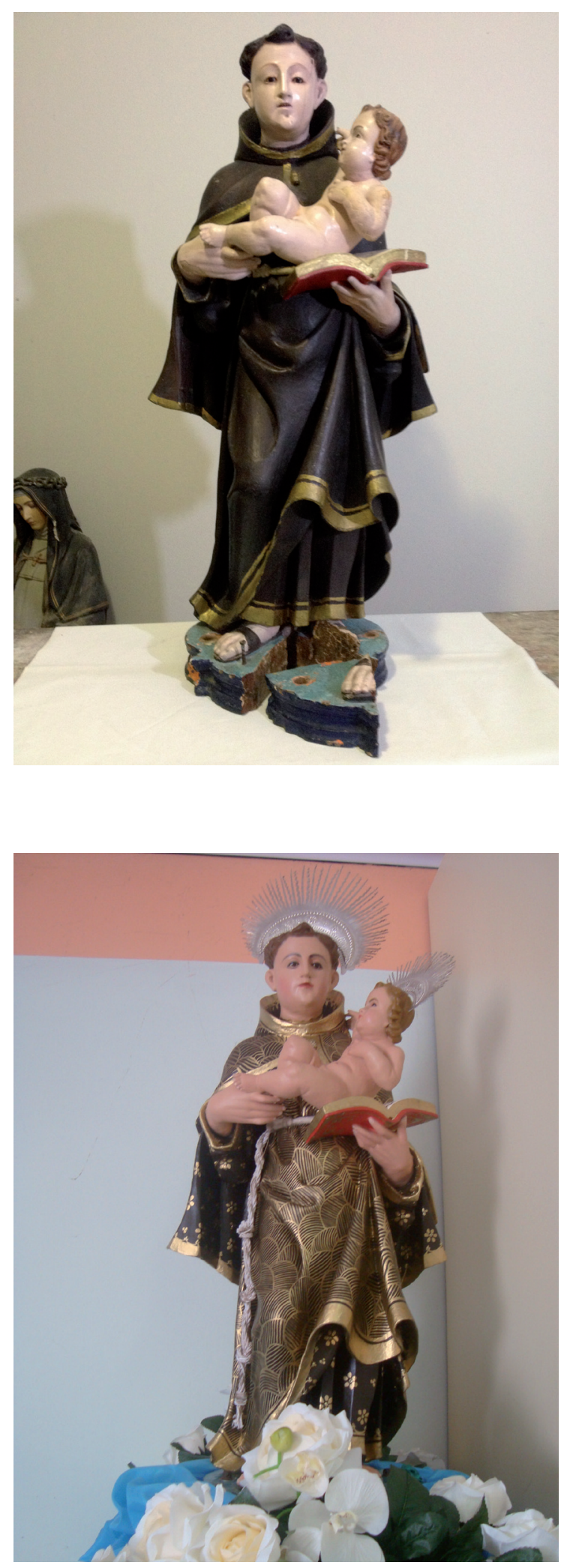
Percebe-se, após o exposto, que os problemas encontrados nas igrejas são diferentes dos museus pela própria rotina interna e necessidades de uso, intrínsecos à sua função.

As intervenções inadequadas também ocorrem por vezes em museus, mas são muito mais comuns nas igrejas, onde faltam informações e esclarecimentos sobre a importância histórica, artística e cultural das obras sacras e sobre os procedimentos corretos para sua conservação ou restauração. Nas igrejas, é muito comum que pessoas queiram "restaurar" imagens dos santos dos quais são devotas. Muitas vezes, os padres permitem que elas retirem essas imagens das igrejas para fazer intervenções. $\mathrm{O}$ resultado geralmente é desastroso. Em muitos casos, as intervenções inadequadas danificam o acervo sacro de modo irreversível.

São consideradas inadequadas as intervenções que não obedecem aos critérios e procedimentos adotados e reconhecidos pelas instituições responsáveis pela preservação do patrimônio cultural. Essas intervenções são realizadas com boas intenções, mas por pessoas que não estão tecnicamente capacitadas. Para evitar intervenções inadequadas, é preciso tomar todos os cuidados possíveis. Antes de qualquer restauração, um técnico especializado deve fazer um projeto e consultar os órgãos responsáveis pelo patrimônio.

A idoneidade do restaurador e a comprovação de seus conhecimentos teóricos e capacidade técnica são fundamentais e devem ser atestados antes de sua contratação para qualquer serviço. O caso de Cecília Gimenez e sua intervenção catastrófica na pintura Ecce Homo em uma igreja espanhola ficaram famosos mundialmente. Casos assim não são exceção e existem exemplos nas igrejas catarinenses. Em Laguna, houve um caso similar na Igreja de Santo Antônio dos Anjos de Laguna. A imagem (Figura 3) apresentava o pedestal quebrado e saiu da igreja, segundo o pároco local, apenas para sua colagem. A pessoa que levou a imagem a devolveu completamente descaracterizada. $\mathrm{O}$ pároco contatou o Iphan, que por sua vez chamou o Atecor para verificar a possibilidade de retirada das intervenções da falsa restauradora, pois, segundo ele, os fiéis não mais reconheciam a imagem e acreditavam que essa tivesse sido trocada, tamanha a diferença apresentada (Figura 4).

Essa intervenção não é uma restauração, foi criada uma nova obra a partir do suporte da antiga, cobrindo a imagem inteiramente com uma nova repintura e colando uma corda à cintura do santo. Esse exemplo serve de 
alerta. Grande parte das pessoas que se arriscam a realizar intervenções nas obras de arte sacra são devotos frequentadores da igreja, bem intencionados, mas sem conhecimentos técnicos. Muitos outros são santeiros, habituados a criar ou pintar imagens sacras e não a restaurá-las e desconhecem os limites e diferenças essenciais entre essas duas práticas.

O proprietário é responsável pela conservação do bem cultural, devendo defender, respeitar e dar manutenção ao bem. Sempre que detectar a necessidade de restauração nos bens do acervo, deve consultar restauradores especialistas naquela tipologia de bem e os órgãos responsáveis pelo patrimônio. Esses órgãos darão orientação, fornecerão as necessárias autorizações e procederão ao acompanhamento e fiscalização da restauração. No caso de patrimônio tombado, a autorização do órgão responsável pelo tombamento é imprescindível antes do início de qualquer intervenção.

\section{CONSIDERAÇÕES FINAIS}

Os objetivos do seminário foram alcançados com êxito. A partir do seminário e da publicação do Caderno de orientações foi iniciada a conscientização e disseminação de informações para a salvaguarda dos bens sacros. O Caderno de orientações foi enviado a todas as dioceses do estado de Santa Catarina para que chegue às mãos dos párocos e paroquianos responsáveis pela manutenção e preservação das igrejas. Trata-se de um guia prático, com orientações para situações cotidianas das igrejas. Tanto o seminário quanto o caderno são instrumentos importantes de capacitação para os guardiões do patrimônio sacro, para que possam auxiliar na salvaguarda de forma eficiente, resguardando o acervo dos diversos fatores que concorrem para a deterioração e perda do riquíssimo patrimônio religioso.

Durante o I Seminário foi percebida a necessidade de a Igreja em nosso estado dispor de um corpo técnico com profissionais habilitados, com conhecimentos técnicos específicos em conservação de bens culturais.

O II Seminário de Conservação de Igrejas e Arte Sacra de Santa Catarina já está sendo organizado e tem como um de seus principais objetivos lançar uma proposta para que a igreja contrate um conservador para cada diocese. Esses profissionais poderiam planejar ações efetivas para a preservação do acervo sacro, orientar outras pessoas que lidam diretamente com esses bens e multiplicar conhecimentos específicos. 
Dessa forma, poderiam compor equipes bem treinadas, distribuir funções e delegar atividades. O Atecor se coloca à disposição da Igreja, oferecendo capacitação aos conservadores contratados pelas dioceses. Espera-se, assim, promover uma salvaguarda mais efetiva do patrimônio sacro.

\section{REFERÊNCIAS}

BALDISSERI, Dom Lorenzo. Bens culturais no Acordo Brasil - Santa Sé, Cadernos de História, v. 13, n. 18, 2012. Disponível em: <http://periodicos.pucminas.br/index.php/cadernoshistoria/ issue/view/233> Acesso em 3 ago. 2015.

BRASIL. Decreto n. 7.107, de 11 de fevereiro de 2010. Promulga o Acordo entre o Governo da República Federativa do Brasil e a Santa Sé relativo ao Estatuto Jurídico da Igreja Católica no Brasil, firmado na Cidade do Vaticano, em 13 de novembro de 2008. Disponível em: <http:// www.planalto.gov.br/ccivil_03/_Ato2007-2010/2010/Decreto/D7107.htm>. Acesso em 20/08/2015

CORREIA, Marcelino Donizeth de Melo (Org.). Conservação de bens culturais sacros no estado de Santa Catarina: caderno de orientações. Florianópolis: FCC. 2014. 84p. Disponível em: <http://www.fcc.sc.gov.br/patrimoniocultural//arquivosSGC/DOWN_140743Cartilha_ Patrimonio_Sacro_web.pdf $>$ Acesso em 19 ago. 2015.

G1 Bahia. Imagens mostram furto de castiçal do século XVIII em igreja de Salvador. G1, 3 out. 2012. Disponível em: <http://g1.globo.com/bahia/noticia/2012/10/imagens-mostram-furto-de-castical-do-seculo-xviii-em-igreja-de-salvador.html> Acesso em 6 ago. 2015.

SANTA CATARINA. Arte sacra patrimônio catarinense: inventário de bens móveis sacros imaginária e pintura - etapa 1. Florianópolis: Vitelli Design, 2008.

SANTA CATARINA. Arte sacra patrimônio catarinense: inventário de bens móveis sacros etapa 2. Florianópolis: DIOESC, 2010.

SCHIO, Daisy. Imagem de São Miguel Arcanjo furtada em 1979 em Biguaçu é recuperada pela Policia Federal. Notícias do Dia, 12 dez. 2011. Disponível em: <http://ndonline.com.br/ florianopolis/noticias/21771-imagem-de-sao-miguel-arcanjo-furtada-em-1979-em-biguacu-e-recuperada-pela-policia-federal.html> Acesso em 12 jun. 2015. 